\title{
Comparison of Next-Generation Sequencing Versus Biological Indexing for the Optimal Detection of Viral Pathogens in Grapevine
}

\author{
Maher Al Rwahnih, Steve Daubert, Deborah Golino, Christina Islas, and Adib Rowhani
}

Department of Plant Pathology, University of California, Davis 95616.

Accepted for publication 2 February 2015.

\begin{abstract}
Al Rwahnih, M., Daubert, S., Golino, D., Islas, C., and Rowhani, A. 2015. Comparison of next-generation sequencing versus biological indexing for the optimal detection of viral pathogens in grapevine. Phytopathology 105:758-763.

A bioassay is routinely used to determine the viral phytosanitary status of commercial grapevine propagation material in many countries around the world. That test is based on the symptoms developed in the field by specific indicator host plants that are graft-inoculated from the

vines being tested. We compared the bioassay against next-generation sequencing (NGS) analysis of grapevine material. NGS is a laboratory procedure that catalogs the genomic sequences of the viruses and other pathogens extracted as DNA and RNA from infected vines. NGS analysis was found to be superior to the standard bioassay in detection of viruses of agronomic significance, including virus infections at low titers. NGS was also found to be superior to the bioassay in its comprehensiveness, the speed of its analysis, and for the discovery of novel, uncharacterized viruses.
\end{abstract}

Grapevine, Vitis vinifera, supports an exceptionally diverse range of disease agents. Sixty-five different species of viruses have been identified in this crop (Martelli 2014). Together with five known viroids, this gives grapevine the distinction of supporting a more diverse collection of subcellular pathogens than any other of the world's agricultural crops. The high frequency of virus infection in grapevines (e.g., caused by leafroll viruses [Maliogka et al. 2008] or Grapevine rupestris stem pitting-associated virus (GRSPaV) [Meng et al. 2006]) is a legacy established over thousands of years. Many of the grapevine viruses are transmitted between grapevines by vector organisms in the field. They can also be moved readily between vines during grafting operations (Rowhani et al. 2005). To control the incidence of disease, grapevine propagating materials are routinely monitored and tested before they are certified for release to commercial nurseries in the United States, the European Union, and other grape-growing countries.

The grapevine bioassay is a test for viruses based on a panel of grapevine selections that serve as indicator hosts (Anonymous, 2008). The bioassay detects those disease agents that are designated as of particular agronomic significance both in United States (U.S.) federal quarantine requirements (as determined by the U.S. Department of Agriculture Animal and Plant Health Inspection Service [APHIS]) and in many state certification programs, including that of California. The selections include Cabernet franc ( $V$. vinifera), which generates a diagnostic interveinal reddening and downrolling of leaf margins as an indicator of leafroll disease caused by members of the Closteroviridae; Kober 5BB (V. berlandieri $x$ $V$. riparia), which expresses stem grooving disease associated with infection by Grapevine virus A (GVA); LN33 (Couderc $1613 \times$ $V$. berlandieri), which develops corky-bark symptoms associated with infection by Grapevine virus B; and St. George (V. rupestris), which develops diagnostic leaf symptoms due to infection by

Corresponding author: A. Rowhani; E-mail address: akrowhani@UCDavis.edu

*The $\boldsymbol{e}$-Xtra logo stands for "electronic extra" and indicates that five supplementary tables are published online.

http://dx.doi.org/10.1094/PHYTO-06-14-0165-R

(C) 2015 The American Phytopathological Society
Grapevine fanleaf virus or Grapevine fleck virus, and stem pitting symptoms from infection by GRSPaV. We note that these are not the only grapevine viruses that can be detected with these indicator cultivars. For example, Cabernet franc is also an indicator for the newly discovered Grapevine red blotch-associated virus (D. Golino, unpublished data) and St. George is an indicator for Grapevine asteroid mosaic associated virus. However, the bioassay tests listed above are the ones required by APHIS and/or the State of California for grape material being screened for viruses in our laboratory so we focus on them for this analysis.

The occurrence of the majority of agronomically significant grapevine viral diseases (Rowhani et al. 2005) is evaluated based on the symptoms induced by graft inoculations to the above panel of indicator vines. The evaluation also includes mechanical inoculation of extracts of test vines to a panel of herbaceous indicator plants. Evaluation of infection symptoms from these two inoculation tests is referred to here as "the bioassay." The test has the capacity to detect previously unknown agents. But the bioassay also has its limitations. The test on grapevine indicator hosts identifies the presence of disease but further testing is required to confirm the identity of the specific causative viral pathogen(s). Compared with more modern assay systems, this lack of specific identification of viral species is one of the procedure's technical draw backs.

Next-generation sequencing (NGS) provides an alternative approach for the identification of viral pathogens in grapevine (Adams et al. 2009; Barba et al. 2014; Kreuze et al. 2009). NGS is a continually improving technology for genomic analysis (Brister et al. 2014; Massart et al. 2014; Mokili et al. 2012). With this automated procedure, the totality of all the genomic DNA and RNA sequences in a sample is produced as a data set by computer analysis of deep sequencing data. Pathogens are identified by comparisons of the information in the data set against the database of all known pathogen genomic sequences.

NGS detection of viruses is not limited by viral strain differences and does not change with environmental conditions. Asymptomatic infections are identified by the protocol, as are those caused by previously unknown viruses (Al Rwahnih et al. 2013; Candresse et al. 2014; Zhang et al. 2011). Those unknown viruses are characterized by identifying distant homologies they share with 
genomic sequences of their known congeneric species (Barzon et al. 2011).

The capacity of NGS to characterize the virome of an infected grapevine was first demonstrated by Al Rwahnih et al. (2009). In that case the technique identified the previously unknown Grapevine Syrah virus 1, against a background of much higher titers of GRSPaV and Grapevine rupestris vein feathering virus. Further discoveries of undescribed grapevine viruses by NGS include that of Grapevine vein-clearing virus (Zhang et al. 2011), Grapevine red blotch associated virus (Al Rwahnih et al. 2013), Grapevine virus F (Al Rwahnih et al. 2012b), and Grapevine Pinot gris virus (Giampetruzzi et al. 2012).

The comprehensive breadth of NGS has been useful in the characterization of the virome of an entire vineyard (Coetzee et al. 2010) and the entire mycovirome of a single grapevine (Al Rwahnih et al. 2011). The technique has become established as a diagnostic tool in the identification of known viruses (Massart et al. 2014; Prabha et al. 2013) and as a procedure for the discovery of unknown viruses. As an example of the latter, a previously unknown grapevine reovirus was discovered in the course of the work presented here (described below). In this study we show that by every measure, the identification of viral pathogens of grapevine by NGS compares at a level of equivalence or superiority with their detection by the biological indexing assay.

\section{MATERIALS AND METHODS}

Plant material. Fifteen grapevine accessions were selected as comparative test material for this study. The selections were known to be infected by a representative spectrum of grapevine pathogenic viruses. Vines were maintained in the Davis grapevine virus collection (Golino, 1992).

The panel of biological index hosts included four grapevine varieties: Cabernet franc, LN 33, St. George and Kober 5BB. Three to six replicates of these four indicator plants were bud chip inoculated from each test plant. Two bud chips were grafted to each indicator plant, and the grafted plants were maintained in the greenhouse for 1 month to allow the graft to heal. After 2 to 4 weeks of acclimatization in a shade house, the number of surviving buds were counted; one viable bud out of two was scored as successful bud take. Successfully grafted plants were then planted in the field. Symptoms were evaluated 1 to 1.5 years after inoculation by at least two observers. Tests in which at least two plants were symptomatic were scored as positive; if just one plant was symptomatic, the test was repeated. Six replicates of each graft inoculation from source plants carrying Grapevine leafroll-associated virus-2 and -3, GVA and GVB, Grapevine fanle af virus, Tomato ringspot virus, Grapevine fleck virus, and GRSPaV were run as positive controls; uninfected controls were maintained in parallel (Rowhani et al. 1997, 2005) and similarly scored. To screen for sap-transmissible viruses, samples from the test plants were mechanically inoculated to a panel of herbaceous indicator plants (Rowhani et al. 2005) including: Chenopodium amaranticolor, C. quinoa, Cucumis sativus, and Nicotiana clevelandii (4, 8, 5, and 2 plants, respectively, per test). Young leaves from test grape plants were homogenized in chilled $0.05 \mathrm{M}$ sodium phosphate buffer, $\mathrm{pH} 7.4$, containing $2 \%$ nicotine. The resulting extracts were rubbed onto carborundum-dusted leaves of the indicator plants. Inoculated indicator plants, including positive controls and water-blank negative controls, were maintained in a greenhouse and scored for symptoms 7 to 15 days postinoculation.

Double-stranded RNA extraction and deep sequencing of nucleic acid extracts from bark scrapings. A nucleic acid fraction enriched for double-stranded ribonucleic acid was extracted from $30 \mathrm{~g}$ of bark scrapings for each sample, as per Routh et al. (1998) but without the DNase and RNase treatments. Complementary DNA was prepared using the SuperScript II Reverse transcription kit (Life Technologies, Grand Island, NY) primed with random hexamers $(300 \mathrm{ng} / \mu \mathrm{l})$ and amplified using the GenomePlex complete whole genome amplification kit (Sigma-Aldrich, St. Louis, MO) as per manufacturer's instructions, but without the fragmentation step. The amplified DNA preparation was purified using a PCR cleanup kit (Sigma-Aldrich) and the DNA quality was verified as described previously (Al Rwahnih et al. 2009).

Sequence data were generated by Eureka Genomics Inc. (Hercules, CA) as described in Al Rwahnih et al. (2013). Approximately 6 million unique reads were generated from each sample. Reads were trimmed using the CLC Bio Genomic Workstation trimming tool, and then they were mapped against the grapevine genome (http:// www.genoscope.cns.fr/externe/GenomeBrowser/Vitis/) to subtract the host background. Contigs were then built from the unmapped reads. Assemblies were created using idba_ud (Peng et al. 2012) with k-mer values from 29 to 49, with the highest-ranking assemblies identified by idba_ud. NCBIs BLASTx program (http://www.ncbi. nlm.nih.gov/BLAST) was used to compare contigs to references, using parameters that were chosen to match the default parameters of the CLC Bio Genomics Workstation (mismatch cost of 2, indel costs of 3 , a similarity fraction of 0.8 over a length fraction of 0.5 ). An E-value cutoff of $1 \mathrm{e}-3$ was used to reduce the chance of false positives. That program was also used to compare the grapevine reovirus genome against the genomes of other phytoreoviruses. Percentages of genomic coverage were computed using Bedtools (Quinlan and Hall 2010).

Virus abbreviations. Grapevine virus- $A$, $-B$, and -E; GRSPaV: Grapevine rupestris stem pitting-associated virus; GFkV: Grapevine fleck virus; GFLV: Grapevine fanleaf virus; sGFLV: satellite GFLV; ToRSV: Tomato ringspot virus; GRVFV: Grapevine rupestris veinfeathering virus; GRBaV: Grapevine red blotch-associated virus; GSyV-1: Grapevine Syrah virus-1; GCSV: Grapevine Cabernet Sauvignon virus; HSVd: Hop stunt viroid; and GYSVd: Grapevine yellow speckle viroid-1.

\section{RESULTS}

For the comparison described here, we chose a set of grape accessions (listed in Table 1) that were known to be infected with viruses of regulatory significance to the grape growing industry. Significant infections are defined here as associated with nepo-, viti-, macula-, and leafroll viruses listed as actionable by the California Department of Food and Agriculture Grapevine Registration and Certification Program (http://www.cdfa.ca.gov/plant/ pe/nsc/docs/regs/ccr_3024_grapevine.pdf) and the Special Departmental Permit for importation of Vitis issued to coauthor Golino by USDA-APHIS; to the authors' knowledge there is no public access to the conditions of individual permits that are issued on an individual basis by application to the APHIS permitting website (http://www.aphis.usda.gov/wps/portal/aphis/resources/ permits). No bioassay indication of disease associated with any of these viruses is permissible in grapevine accessions qualified for release from quarantine or certified for inclusion in the California regulatory program (Rowhani et al. 2005).

This set of accessions was screened here simultaneously using both the biological indexing assay and NGS analysis. Fifteen grapevine accessions from 13 grapevine cultivars were represented, with a Kober 5BB accession serving as an uninfected control.

Detection of viral disease agents using the standard biological indexing procedure. Disease symptoms in indicator vines were scored in the appropriate season in the second year after graft inoculation. (The specific identifications of viruses associated with the disease symptoms in the index plants listed in Table 1 are based on virus-specific reverse transcription-polymerase chain reaction (RT-PCR) analyses of those symptomatic plants). All of the grapevine accessions in the panel of vines under analysis (hereafter: test vines) were found to be carrying multiple virus infections (data used to generate the infection ratings is in Supplementary Table S2).

From the 60 grapevine index host analyses listed in Table 1, 37 were symptomatic. The analysis on indicator host St. George was 
further divided into foliar and stem symptoms; examples of multiple infection were commonly found on the individual St. George indicator plants. Foliar fleck symptoms on two St. George plants were interpreted as indicative of infection by GFkV; in one case oakleaf and ringspot symptoms on the foliage indicated GFLV infection; stem-pitting disease symptoms in 12 tests were interpreted as indicative of infection by GRSPaV. In total, six viral species and one generic group (leafroll viruses) are listed in the bioassay results in Table 1 .

The bioassay protocol also includes a screening of extracts from test vines by inoculation to herbaceous indicator hosts. Though this screen is relatively insensitive to many grapevine pathogens (Conti et al. 1980) it does reveal some viruses not well detected by the woody index hosts (Rowhani et al. 2005). In this study, all the herbaceous indicator plants inoculated from the test plants were scored as negative with the exception of positive tests on Chenopodium amaranticolor and Nicotiana clevelandii (2/4 and 2/2 positive/plants tested, respectively), C. quinoa (3/8) and Cucumis sativis (5/5), indicating a ToRSV infection in the Carignan accession. And a positive test on C. quinoa (3/8) indicated a GFLV infection in the St. George accession. These positive tests were confirmed by the NGS analysis, as seen in the corresponding positions in Table 2. However, the NGS data also showed that GFLV was present in accession 2 (Semillon), but that infection went undetected in the herbaceous assay, as well as in the St. George indicator host test. Further, the NGS analysis also showed that GFkV was present in accession 3 (Cabernet Sauvignon), though the infection went undetected in the St. George indicator host assay (all of these NGS detections were confirmed by RT-PCR analysis, data not shown).

Detection of viral genomes by deep sequencing analysis. The same 15 accessions that were tested by biological indexing as described above were subjected to NGS characterization. In this second analysis, the total double-stranded RNA (dsRNA) fraction was extracted from bark scrapings from each test plant. The dsRNA fraction was converted into complementary DNA and amplified (see Methods) into libraries of millions of reads (Supplementary Table S1). The reads were mapped against the grapevine genome, and then contigs were built from the unmapped reads. The contigs derived from viral sequences were identified by their BLAST similarities to viral sequences in the GenBank database. The number of specific viral reads is proportional to the percentage of genome coverage for each virus. (The number of contigs is not proportional to the percentage of coverage; e.g., complete genomic coverage is realized with a single [genomelength] contig.)

In the NGS analysis, 21 plant virus species and strains were detected, most of them multiple times (Table 2) among the accessions in the test plant panel. Two viroids and a satellite RNA were also detected, as was a list of myco/cryptic viruses. The entire process from initial dsRNA isolation and preparation of the cDNA library, through sequencing and bioinformatic analysis took no more than a month to complete, including shipment time of test materials to a commercial sequencing facility.

The NGS assays identified grapevine leafroll viruses to the species level (and divided GLRaV-4 into its strains -5, -6, -9, and -Pr; Table 2), whereas the indicator host bioassay only identified generic leafroll disease. The NGS analysis detected infections by GRVFV, GSyV-1, and GRBaV, which are beyond the scope of the biological index tests (though GRBaV does appear to induce foliar disease symptoms on Cabernet franc indicator hosts; D. Golino, unpublished observations).

Even though we saw no evidence of bioassay false negatives or false positives in control analyses (Supplementary Table S3), this study did reveal inconsistencies between the NGS data and the bioassay results in the test plants. NGS analysis revealed GVA infections in the analyses of the Sangiovese and the Aldo test plants that were not detected by the biological assay. Those infections were confirmed by quantitative RT-PCR analysis (data not shown). NGS also revealed a GRSPaV infection in the Helena test plant that was not detected by the St. George indicator bioassay.

The NGS analysis also detected a virus previously unknown in grapevine: Grapevine Cabernet Sauvignon reovirus (provisional name here GCSV). The virus was found to have 10 genomic segments. The number of GCSV-specific contigs in the Cabernet Sauvignon accession sample 11 was high enough to contain $99 \%$ of the viral genome sequence information. The accession numbers of those 10 contig sequences as submitted to GenBank are listed in Supplementary Table S4. The sequence homologies of these components with those of other phytoreoviruses averaged less than $66 \%$ indicating that GCSV is a distinct viral species. BLAST analysis initially identified GCSV as Raspberry latent reovirus, which is typical of the ambiguous initial identifications that arise for viruses unknown in the database.

NGS detection of low-level infections. The wide range of mycoviruses detected in this study provided for an assessment of the accuracy of the NGS analysis of viruses at low titers. Seventy eight mycoviral genomes or genomic components identified in the test accessions are listed in Supplementary Table S5. The five genomic components of Grapevine associated mycovirus (Al Rwahnih et al. 2011) were represented by 305 contigs. Botrytis porri RNA virus was represented by 149 contigs. The number of mycovirus contigs and species identified in this NGS analysis was greater than the corresponding numbers for the plant viruses. Accessions Marsanne

TABLE 1. Viral infections in 15 accessions scored from bioassay on Cabernet franc (CF), LN33, St. George (SG), and Kober 5BB (K5BB) indicator varieties, and on herbaceous indicator hosts ${ }^{\mathrm{a}}$

\begin{tabular}{|c|c|c|c|c|c|c|c|c|}
\hline Accession no. & Accession & Cultivar & Infections identified & $\mathrm{CF}$ & LN33 & SG & K5BB & Herbaceous \\
\hline 1 & LR102 & Marsanne & LR GVA GVB GRSPaV & + & + & + & + & - \\
\hline 2 & CB100 & Semillon & LR GVB GRSPaV & + & + & + & - & - \\
\hline 3 & LV89.2 & Cabernet Sauvignon & LR GVB GRSPaV & + & + & + & - & - \\
\hline 5 & LV91.1 & Cabernet Franc & LR GVA GVB GRSPaV & + & + & + & + & - \\
\hline 6 & LV94.4 & Chardonnay & LR GVB GFkV GRSPaV & + & + & + & - & - \\
\hline 7 & CB120 & St. George & GVA GVB GFLV & - & + & + & + & + \\
\hline 8 & $\mathrm{ToSV}_{100}$ & Carignane & LR GRSPaV ToRSV & + & - & + & - & + \\
\hline 11 & LV89.15 & Cabernet Sauvignon & LR GVB GFkV GRSPaV & + & + & + & - & - \\
\hline 12 & LR118 & Helena & LR & + & - & - & - & - \\
\hline 13 & LR119 & Cabernet Sauvignon & LR GRSPaV & + & - & + & - & - \\
\hline 14 & CB101 & Aldo & LR GVB GRSPaV & + & + & + & - & - \\
\hline 15 & LR110 & Italia 3 & LR GRSPaV & + & - & + & - & - \\
\hline
\end{tabular}

${ }^{a}$ Disease symptoms on St. George occurred either on the stem or on the foliage. Infection by individual viruses was verified by both polymerase chain reaction tests and the next-generation sequencing procedure. 
and St. George were seen to support no mycoviruses, but most of the other test vines supported multiple species.

The median number of contigs per specific mycoviral species was one. Their BLAST identifications were often guided by GenBank reference sequences of homologous mycoviruses from nongrapevine sources. As a consequence, the alignments through which these viruses were identified often contained multiple mismatches. As the number of specific contigs and the lengths of those contigs decrease, the percentage genomic coverage for those viruses, and the reliability of their identifications declined (discussed below).

\section{DISCUSSION}

Both biological indexing and NGS analysis are very sensitive assays for the detection of disease-associated virus in Vitis. In the standard bioassay for grapevine viruses, biological amplification by viral replication generates readily detectable disease symptoms in indicator plants, even starting from very low titer grafted viral inoculum. In the NGS procedure, the PCR cascade amplifies very low numbers of specific viral sequences up to detectable numbers of reads.

We found the NGS procedure to be superior to the bioassay in detection sensitivity for the regulated viruses in this data set. All infections detected in the bioassay, including those identified by visible disease symptoms in as few as two out of six test plants, were also detected by NGS. Infections detected by as few as one or two NGS contigs were also usually detected by the biological indexing screen. However, in this study, the biological assay failed to detect infections that were revealed by the NGS analysis in $8.3 \%$ ( 5 per 60 ) of the grapevine indicator host tests. These included failure to produce disease symptoms from GVA infections present in the Sangiovese and the Aldo accessions, from GRSPaV infection in the Helena accession, from GFLV in the Semillon accession, and from GFkV in accession 3 (Cabernet Sauvignon). The herbaceous bioassay detected the GFLV infection in the St. George accession (viz. NGS detection of that GFLV with $55 \%$ viral genomic coverage), but it failed to detect the GFLV infection in the Semillon accession (detected with 15\% genomic coverage in the NGS assay).

In aspects of the comparison between these two methods other than detection sensitivity, such as specificity and reliability, NGS appeared superior to the bioassay. But the most significant distinction between the two methods was in the time to completion for each process. The biological indexing assay required nearly two years to complete under California conditions (and would require even longer in cooler climates; D. Golino, unpublished observations). NGS laboratory assays were completed in weeks. Due to this savings of time and to the costs involved with the grafting and maintenance of test vines in the greenhouse and then in the field, NGS analysis would likely be preferred over biological index testing for most applications.

Historical precedent of the bioassay. The bioassay employs chip bud graft inoculation from candidate grapevine accessions onto indicator grapevine plants. This test once provided the best means of screening grapevine accessions for known viruses, and for discovering unknown viruses in the vineyard. Historical examples of viruses that were first detected by the symptoms they caused in indicator hosts date from the 1950s and the decades just thereafter. The bioassay has persisted, and is now the industry standard (e.g., California Code of Regulations; Title 3. Food and Agriculture, 3024.5) for certification of grapevine stocks (Rowhani et al. 2005).

Bioassay results can be dependent on climatic conditions (Constable et al. 2013), e.g., symptoms of GFLV infection on St. George indicator host can fade and disappear under warmer conditions (Constable et al. 2013). Further, the reliability of the biological assay is dependent on the success of the bud graft inoculation procedure. High rates of bud grafting failure lower confidence in negative test scores, necessitating repeat graft inoculations, which can delay the availability of conclusive results for years.

TABLE 2. Next-generation sequencing detectable virus, viroid, and viral satellite species in the 15 test accessions as listed in Table $1^{\mathrm{a}}$

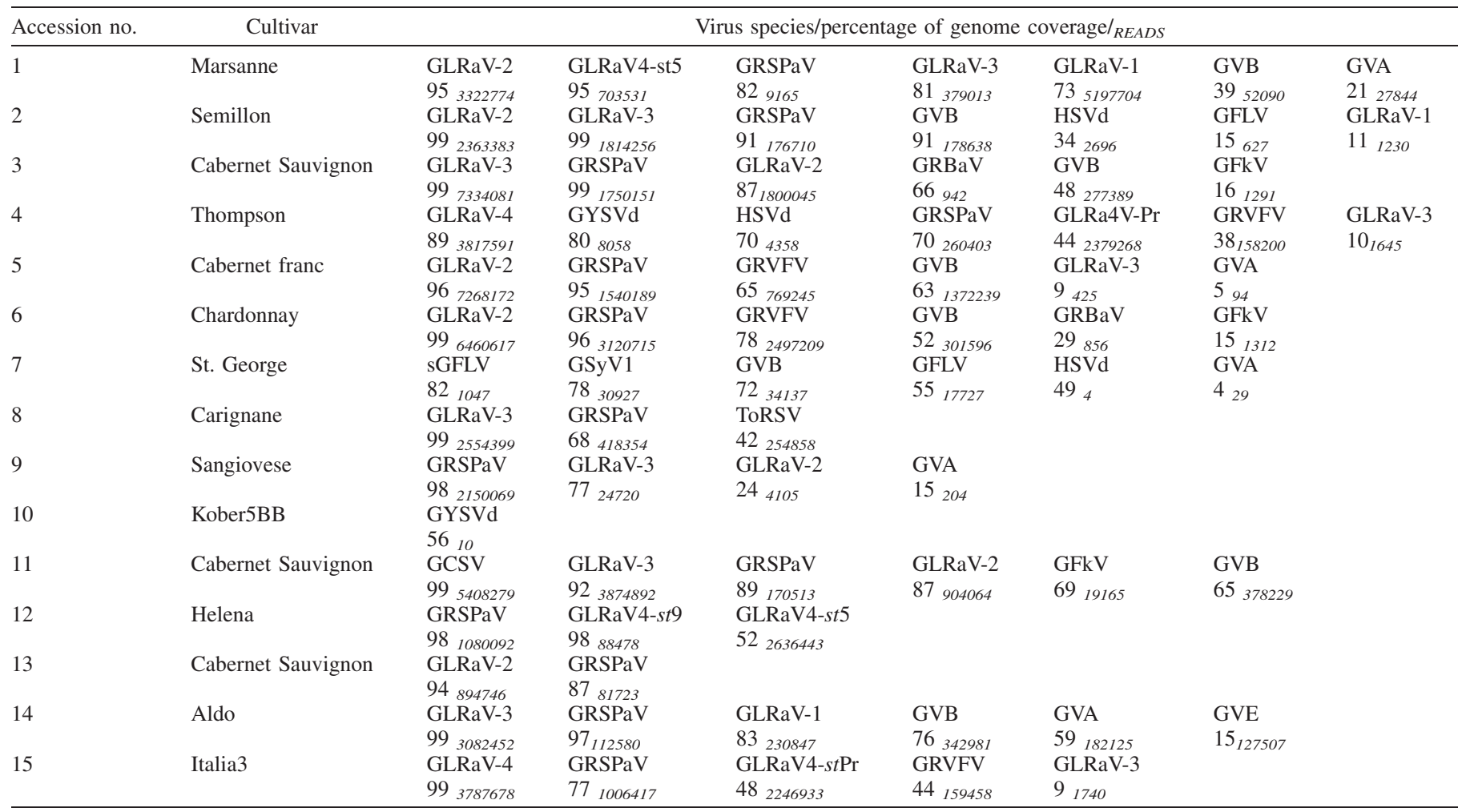

a Species are listed in descending order of the percentage of genomic coverage (listed below each) afforded by the contigs derived from the reads (listed in italics beside the percentage of coverage) identified as specific to each. 
Biological screening could presumably produce a positive indication of infection even if the causative agent was a novel, unknown virus. However, NGS analysis, with its more comprehensive range of viral families detected and its shorter time to experimental conclusion, is currently the preferred technology for the discovery of new viruses. Its effectiveness in this application is exemplified here with the discovery of GCSV.

Advantages of NGS analysis. Whole genome deep sequencing analysis has an advantage over all previous plant virus diagnostics in its all-inclusiveness. As opposed to dedicated biological indexing, as well as to enzyme-linked immunosorbent assay and PCR, NGS analysis is broad spectrum and not species specific. It reveals the entire virome census from test plants, which is a considerable advance over previous species-specific technologies. But the BLAST analytical stage of the process is still dependent on the list of known viral references in GenBank. Unknown viruses are identified by similarities to their nearest known GenBank congeners.

NGS detects a broader range of pathogens than those scored in the bioassay, such as, in this study, the geminivirus-like GRBaV, the marafivirus GRVFV, reovirus GCSV, and the viroids (Table 2). NGS analysis detects a wider range of strain variants than other plant virus assay systems. In this study, variants of GVA and of leafroll viruses detected in the NGS analysis were seen to carry sequence variation extensive enough to preclude annealing with specific PCR primers (data not shown). Such genomic variation could render some viral strains invisible to PCR detection.

Certain agronomically important viral species, such as vitiviruses (Al Rwahnih et al. 2012b; Rosa et al. 2011) and leafroll-associated viruses (Alabi et al. 2011; Al Rwahnih et al. 2012a; Poojari et al. 2013b; Rowhani et al. 1997) include strains that are asymptomatic. These strains might not be detected by their symptoms in the biological assay. Those viruses could nonetheless be virulent in different grapevine varietal backgrounds (Alkowni et al. 2011) or in combination with other pathogens in a mixed infection (Rosa et al. 2011). Such asymptomatic strains are detected by the NGS analysis. The genomic sequence information generated by the NGS analysis is useful for the design of PCR primers that can detect both virulent and asymptomatic strains of such virus species (Maree et al. 2013) during vineyard disease screening and nursery sanitation tests.

The bioassay has the potential to reveal disease associated with unknown species of nepo-, macula-, viti-, and leafroll-viruses, but it would not be expected to reliably detect novel pathogens from other viral families. In contrast, the genomes of unknown pathogens (from all families) would be discovered by the NGS analysis. The discovery of GCSV in this study serves as an example. The bioassay is a qualitative test, scored for infection as either positive or negative. In contrast, NGS analysis data can be quantitated in terms of the number of specific reads produced for each viral species in each sample.

The nucleic acid extraction step in the NGS protocol can be modified to optimize the detection of specific pathogens. Extraction of dsRNA emphasizes the detection of RNA plant viruses (Coetzee et al. 2010) though DNA viruses and cellular pathogens are also detected in those samples. Purification of siRNAs can optimize for the detection of DNA viruses and viroids (Kreuze et al. 2009; Sequin et al. 2014); preparation of a total nucleic acid extract including a step for the exclusion of ribosomal RNAs (Poojari et al. 2013a) can facilitate the detection of bacteria, fungi, and phytoplasmas along with viruses (Adams et al. 2009).

Limitations of NGS analysis. NGS analysis provides informatics data; it does not provide biological observations. Thus, it is not likely to completely replace bioassays. For plants found by NGS to be infected with previously unknown viruses, further biological work will be needed to substantiate and characterize the discovery. The possibility that a particular virus could prove virulent in a different varietal background (Alkowni et al. 2011), or that it could synergize in combination with a second pathogen (Rosa et al. 2011) can only be evaluated through biological analysis. The full potential of an infection detected by NGS through only a few contigs in one particular host can only be assessed using a biological assay with a panel of different hosts.

Limitations to the confidence of NGS identifications arise during the detection of viruses at low titers. In these instances, confidence depends on the fraction of a viral genome that is covered by specific contigs. In situations where the number of reads, or the percentage of genomic coverage is low, the NGS analysis should be repeated to increase confidence in the specific identification of viruses detected by a limited number of contigs. Another low confidence situation arises in plants coinfected with similar viruses at widely different titers. In a coinfection, the detection of the virus with the lowergenomic coverage may have arisen as misidentification of the most variant sequence reads from the higher titer coinfecting virus, e.g., the detection of GLRaV-3 is of low confidence when it is identified by reads data providing only $10 \%$ coverage of its genome (Table 2 , samples 4, 5, and 15) against a background of other leafroll viruses at much higher titers.

A similar lack of confidence arises when a high number of contigs are present, but they map unevenly across the genome, resulting in low over-all genomic coverage. In such cases, coverage concentrated at a small number of positions may have arisen from amplification of a small number of contaminating sequences.

NGS as a replacement for the biological index assay. The findings of this study suggest that NGS screening of new grapevine accessions should provide considerable improvement over the current biological index protocol. NGS analysis could completely replace the biological index screening in many common applications, including (i) for plants that prove to be uninfected, and (ii) for plants found to be infected by well-known pathogens.

The cost of NGS analysis is declining, and the time needed will be shortened further with the advent of self-contained, in-house benchtop deep sequencing analysis capabilities. In contrast to NGS analysis, there are significant considerations involved with the costs of the facilities and labor required for the long-term maintenance of plants used in the biological assay. But the largest cost component of the bioassay protocol is in time lost to the growers while they wait for grapevine accessions to be released from quarantine. If NGS use was accepted for grapevine certification and registration in place of the current industry standard, growers would be able to start propagative increase and virus elimination programs with most new accessions years earlier than they can now.

\section{ACKNOWLEDGMENTS}

We thank A. Durvasula, UC Davis Biotechnology Program, for running the bioinformatics analysis. We thank J. M. Pucket and S. Sim, UC Davis Foundation Plant Services, for help with the bioindexing tests. Funded by the American Vineyard Foundation and by the California Department of Food and Agriculture Fruit Tree, Nut Tree and Grapevine Improvement Advisory Board.

\section{LITERATURE CITED}

Adams, I. P., Glover, R. H., Monger, W. A., Kemford, R., and Jackervicience, E. 2009. Next generation sequencing and metagenomics: A universal diagnostic tool in plant virology. Mol. Plant Pathol. 10:537-545.

Al Rwahnih, M., Daubert, S., Golino, D., and Rowhani, A. 2009. Deep sequencing analysis of RNAs from a grapevine showing Syrah decline symptoms reveals a multiple virus infection that includes a novel virus. Virology 387:395-401.

Al Rwahnih, M., Daubert, S., Urbez-Torres, J., and Rowhani, A. 2011. Deep sequencing evidence from single grapevine plants reveals a virome dominated by mycoviruses. Arch. Virol. 156:397-403.

Al Rwahnih, M., Dave, A., Anderson, M., Rowhani, A., Uyemoto, J. K., and Sudarshana, M. R. 2013. Association of a DNA virus in grapevines affected by red blotch disease in California. Phytopathology 103:1069-1076.

Al Rwahnih, M., Dolja, V., Daubert, S., Koonin, E., and Rowhani, A. 2012a. Genomic and biological analysis of grapevine leafroll-associated virus 7 reveals a possible new genus within the family Closteroviridae. Virus Res. 163:302-309. 
Al Rwahnih, M., Sudarshana, M., Uyemoto, J., and Rowhani, A. 2012b. Complete genome sequence of a novel vitivirus isolated from grapevine. J. Virol. 86:9545.

Alabi, O. J., Al Rwahnih, M., Karthikeyan, G., Poojari, S., Fuchs, M., Rowhani, A., and Naidu, R. A. 2011. Grapevine leafroll-associated virus 1 occurs as genetically diverse populations. Phytopathology 101:1446-1456.

Alkowni, R., Zhang, Y.-P., Rowhani, A., Uyemoto, J. K., and Minafra, A. 2011. Biological, molecular, and serological studies of a novel strain of grapevine leafroll-associated virus 2. Virus Genes 43:102-110.

Anonymous. 2008. Pathogen-tested material of grapevine varieties and rootstocks. EPPO Bull. 38:422-429.

Barba, M., Czosnek, H., and Hadidi, A. 2014. Historical perspective, development and applications of next-generation sequencing in plant virology. Viruses 5:106-136.

Barzon, L., Lavezzo, E., Militello, V., Toppo, S., and Palu, G. 2011. Applications of next-generation sequencing technologies to diagnostic virology. Int. J. Mol. Sci. 12:7861-7884.

Brister, R. J., Ako-adjei, D., Bao, Y., and Blinkova, O. 2014. NCBI viral genomes resource. Nucleic Acids Res.

Candresse, T., Filloux, D., Muhire, B., Julian, C., and Galzi, S. 2014. Appearances can be deceptive: Revealing a hidden viral infection with deep sequencing in a plant quarantine context. PLoS ONE 9:e102945.

Coetzee, B., Freeborough, M. J., Maree, H. J., Celton, J. M., and Rees, D. J. 2010. Deep sequencing analysis of viruses infecting grapevines: The virome of a vineyard. Virology 400:157-163.

Constable, F. E., Connellan, J., Nicholas, P., and Rodoni, G. C. 2013. The reliability of woody indexing for detection of grapevine virus-associated diseases in three different climatic conditions in Australia. Aust. J. Grape Wine Res. 19:74-80.

Conti, M., Milne, R. G., Luisoni, E., and Boccardo, G. 1980. A closterovirus from a stem-pitting-diseased grapevine. Phytopathology 70:394-399.

Giampetruzzi, A., Roumi, V., Roberto, R., Malossini, U., Yoshikawa, N., La Notte, P., Terlizzi, F., Credi, R., and Saldarelli, P. 2012. A new grapevine virus discovered by deep sequencing of virus- and viroid-derived small RNAs in CV Pinot gris. Virus Res. 163:262-268.

Golino, D. A. 1992. The Davis grapevine virus collection. Am. J. Enol. Vitic. 43:200-205

Kreuze, J. F., Perez, A., Untiveros, M., Quispe, D., and Fuentes, S. 2009. Complete viral genome sequence and discovery by deep sequencing of small RNAs: A generic method for diagnosis, discovery, and sequencing of virus. Virology 388:1-7.

Maliogka, V. I., Dovas, C. I., and Katis, N. I. 2008. Evolutionary relationships of virus species belonging to a distinct lineage within the Ampelovirus genus. Virus Res. 135:125-135.

Maree, H. J., Almeida, R. P., Bester, R., Chooi, K. M., and Cohen, D. 2013. Grapevine leafroll-associated virus 3. Front. Microbiol. 4:82-93.

Martelli, G. P. 2014. Grapevine-infecting viruses. J. Plant Pathol. 96:7-8.
Massart, S., Olmos, A., Jijakli, H., and Candresse, T. 2014. Current impact and future directions of high throughput sequencing in plant virus diagnostics. Virus Res. 188:90-96.

Meng, B., Li, C., Wang, W., Goszczynski, D., and Gonsalves, D. 2005. Complete genome sequences of two new variants of Grapevine rupestris stem pitting-associated virus and comparative analyses. J. Gen. Virol. 86: 1555-1560.

Meng, B., Ribelo, A., and Fisher, H. 2006. Genetic diversity analyses of Grapevine rupestris stem pitting-associated virus reveal distinct population structures in scion versus rootstock varieties. J. Gen. Virol. 87: 1725-1733

Mokili, J. L., Rohwer, F., and Dutilh, B. E. 2012. Metagenomics and future perspectives in virus discovery. Curr. Opin. Virol. 2:63-77.

Peng, Y., Leung, H. M. C., Yiu, S. M., and Chin, F. Y. L. 2012. IDBA-UD: A de novo assembler for single-cell and metagenomic sequencing data with highly uneven depth. Bioinformatics 28:1420-1428.

Poojari, S., Alabi, O. J., Fofanov, V. Y., and Naidu, R. A. 2013a. A leafhoppertransmissible DNA virus with novel evolutionary lineage in the family Geminiviridae implicated in grapevine red leaf disease by next-generation sequencing. PLoS ONE 8:e64194.

Poojari, S., Alabi, O. J., and Naidu, R. A. 2013b. Molecular characterization and impacts of a strain of Grapevine leafroll-associated virus 2 causing asymptomatic infection in a wine grape cultivar. Virol. J. 10:324-330.

Prabha, K., Baranwal, V. K., and Jain, R. K. 2013. Applications of next generation high throughput sequencing technologies in characterization, discovery and molecular interaction of plant viruses. Indian J. Virol. 24: $157-165$

Quinlan, A. R., and Hall, I. M. 2010. BEDTools: A flexible suite of utilities for comparing genomic features. Bioinformatics 26:841-842.

Rosa, C., Jimenez, J. F., Margaria, P., and Rowhani, A. 2011. Symptomatology and effects of viruses associated with rugose wood complex on the growth of four different rootstocks. Am. J. Enol. Vitic. 62:207-213.

Routh, G., Zhang, Y. P., Saldarelli, P., and Rowhani, A. 1998. Use of degenerate primers for partial sequencing and RT-PCR-based assays of grapevine leafroll-associated viruses 4 and 5. Phytopathology 88:1238-1243.

Rowhani, A., Uyemoto, J. K., and Golino, D. A. 1997. A comparison between serological and biological assays in detecting grapevine leafroll-associated viruses. Plant Dis. 81:799-801.

Rowhani, A., Uyemoto, J. K., Golino, D. A., and Martelli, G. P. 2005. Pathogen testing and certification of Vitis and Prunus species. Annu. Rev. Phytopathol. 43:261-278.

Seguin, J., Rajeswaran, R., Malpica-Lopez, N., Martin, R. R., and Kasschau, K. 2014. De novo reconstruction of consensus master genomes of plant RNA and DNA viruses from siRNAs. PLoS ONE 9:e88513.

Zhang, Y., Singh, K., Kaur, R., and Qui, W. 2011. Association of a novel DNA virus with the grapevine vein-clearing and vine decline syndrome. Phytopathology 101:1081-1090. 